\title{
Challenges Students Encounter in their Study of Pronunciation in Ghana: A Case of Osei Kyeretwie Senior High School
}

\author{
Daniel Afrifa-Yamoah ${ }^{1}$, Emmanuel Kyei ${ }^{1}$, Isaac Adubofour ${ }^{2}$ and Felicia Sarpong ${ }^{3}$ \\ ${ }^{1}$ Akenten Appiah-Menka University of Skill Training and Development, Ghana \\ ${ }^{2}$ University of Development Studies, Ghana, ${ }^{3}$ Kumasi Academy, Ghana \\ *Corresponding Mail: danielafrifayamoah@gmail.com
}

\begin{abstract}
The purpose of this study was to establish the challenges Ghanaian students face in learning English language pronunciation. The study employed a qualitative approach through administering a recording test on the learners and a questionnaire that required teachers to write their views and ideas regarding the problem under investigation. The study collected data from 50 randomly selected students out of a total number of 300 from the final year classes of Osei Kyeretwie Senior High School and 25 out of 45 teachers of English from the languages department. The study found that a large number of the learners mispronounced selected vowels and consonants, thus confirming the reality that pronunciation problem persisting in Ghanaian secondary schools. The problem of poor pronunciation was found to be related to the teaching and learning strategies employed in teaching pronunciation, unskilled teachers and the influence of mother tongues. The study recommends that teacher trainees in English language from institutions of higher learning should be exposed to the appropriate strategies of teaching good pronunciation. Furthermore, regular inservice training should be organized for the teachers of English in senior high schools to equip them with the current approaches to teaching pronunciation. Lastly, stakeholders of education in the country should provide well-resourced language laboratories for senior high schools to enable students to practice phonetics effectively.
\end{abstract}

Keywords: Senior High School Learners, English pronunciation, language laboratory, the learning process

\section{Introduction}

In recent times, the development of science and technology has made communicating with speakers from places other than one's speech community a necessity. This partly explains the rise of the English language to the status of a universal tool of communication. Even in Ghana, it is extremely important as English is a mandatory subject in the Ghanaian educational system.

According to Moosa (1972) and Homidan (1984), most Arab students are handicapped when it comes to sounds with which they are not familiar, such as $/ \mathrm{v} /, / \mathrm{p} /, / \mathrm{p} /$. Nation and Newton (2009) asserts that when some tutors and learners lament about worries in speaking, they are often talking about pronunciation. The importance of good pronunciation can therefore never be overemphasized in one's quest of learning a second language such as the English language. This assertion is supported by Derwing and Munro (2005) who note that, "having good pronunciation of the language can help in normal communication, particularly intelligibility."

To ensure the effective Communicative Language Teaching (CLT), learners must possess a good pronunciation competence in addition to having a good knowledge of vocabulary, appropriate grammar and the four language skills (speaking, writing, reading and listening). Correct articulation of words is therefore necessary to achieve good English language proficiency. Consequently, studying English pronunciation is key to the study of English as a second or foreign language for teaching and learning, examinations and for other purposes. Mastery of English language improves learners' chances to having good jobs in the future, and enables them to communicate with foreigners successfully if they have a chance and the need. 
Despite the significance of good pronunciation, most Ghanaian students struggle with appropriate English pronunciation. This challenge has come about as a result of the fact that much of classroom teaching is centered on grammar, comprehension and composition with less or no attention paid to pronunciation. By this, one may not be far from right to assert that teachers of English are also contributors when it comes to the challenges learners encounter relative to good English pronunciation. Pronunciation appears to be the most serious challenge that students encounter in studying English as a second language. This has been a major cause for students' failure in the oral English examination. Based on this background, the study was designed to answer the following research questions:

1. What are the challenges of second language learners in English pronunciation among the Osei Kyeretwie Senior High School Students?

2. What are the areas of difficulty and the contributing factors toward the pronunciation challenges among the learners under investigation?

\section{Literature Review}

Language is a system of interaction that relies on the use of sound symbols in the expression of meaning, ideas or thoughts (Yule, 2017). Proper use of language in communication must be dominant in the classroom of English language, if effective learning has to take place. Several scholars on $L_{2}$ learning assert that English pronunciation difficulties among non-native speakers are similar; however, differences could be identified based on each one's native language. Therefore, the importance of the English language as a second language in Ghana cannot be overemphasized. This study sought to establish the challenges of second language learners in English pronunciation, the areas of difficulty and the contributing factors toward the pronunciation challenges among the learners under investigation.

\section{Teaching English Pronunciation}

Several teachers and students of English often do not prioritize the teaching and learning of pronunciation (Asante-Nimako, 2018) probably because they do not appreciate its value in communication. It cannot be gainsaid that a lot of misunderstanding in communication, especially between people from different linguistic backgrounds could be associated with mispronunciation of words. The aim behind teaching English pronunciation is to enable students to communicate intelligibly with other people, including those from native speaker countries. Nevertheless, good pronunciation is an area that is largely neglected by teachers and students alike. Teaching good pronunciation equips students with effective speaking and listening skills. Contemporarily, there are several approaches to teaching pronunciation which should be worth of consideration by teachers of English as a second language. The communicative approach patented in the 1980s proposed that the teaching and learning of English language must be based on the use of the language to communicate. Therefore, understandable articulation of words and sentences is principal for effective communication to be achieved.

It is then not surprising that certain scholars such as O'Connor (1997) argue that prominence should be given to rhythm, word stress, sentence stress and intonation, which is the ideal approach to teaching pronunciation to $L_{2}$ learners as these factors are a key to effective communication. The demands and peculiar expectations from second language learning indicated above suggests that teachers of English as a second language who are non-native speakers of English and non-native students of English demand distinctive care and support in pronunciation.

\section{Factors Affecting Pronunciation}

Based on the background of this study, the factors that influence the learning of language pronunciation are discussed below.

\section{Accent, Stress, Rhythm, Intonation}

Acoustic assessments of human speech reveals that there are features related to rise and fall in pitch, timing and cues. All these factors complement one another towards effective communication. O'Connor (1997) defines accent as a unique manner of the pronunciation of a language, one related to a specific nation, area, or social class. He further argues that in learning pronunciation, there are certain significant features that form the basis: accent, stress, rhythm, and intonation. Schaetzel (2009) defines accent as the accumulative auditory influence of characteristics of pronunciation that tell the background of a person regionally or socially. Native speaker's competence is and must be the target of every $L_{2}$ learner in any language. Roach (2002) asserts that stress syllables are usually 
termed as those syllables with an utterance that is longer, louder and higher in pitch. That is the degree of force with which a syllable or a word is articulated. Even words that have more than one syllable always contain one that is produced louder than the other(s). Stress plays a key role in English pronunciation because the meaning of most English words, especially words with the same structure, depends on stress. A speaker with good mastery of stress placement is so enjoying listening to. Such individuals are seen as the very extraordinary communicators of the language.

In speaking, there is a kind of modulation of the voice. The fall and rise of the voice are termed as intonation. According to O'Connor (1997), intonation is the form of waves of language acquires in speech. It is sometimes referred to as the melody or music of language. The relationship between stressed and unstressed syllable of language is termed rhythm. Roach (2002) maintains that rhythm is generally produced by making certain notes to stand out of the form of others by being louder or longer or higher. Crystal (2003) noted that rhythm is structured according to regulation of the timing of the stressed syllables. English is said to be stresstimed whereas Akan, which is the dominant language spoken by the respondents, is syllabletimed. Rhythm is beneficial in communication and permits a speaker to categorize speech into words or other units.

\section{Age}

People from different age backgrounds do not use language the same way. In fact, certain physiological and biological factors ensure that quality of speech sounds as produced by individuals from different ages differ. According to Birdsong (2004), most adult second language learners never achieve the nativespeaker proficiency. The native accent of the $L_{2}$ learner of English continues to interfere with their ability to communicate efficiently. The proponents of the Critical Period Hypothesis assert that there is a natural timetable for language learning and acquisition. According to this timetable, beyond puberty, it is more difficult to acquire a foreign-like accent. Children between the ages of 0 and 10 have the potential to attain a foreign-resembling accent if they have happened to grow in a native speaker country. Younger people then have precise consciousness of the sounds of the new language. Muñoz and Singleton (2011) theorized that language might be assimilated only by a critical period, ranging from early infancy until adolescence. If a person learns English at a tender age, the fellow forms all thoughts in English and uses the language naturally.

\section{Enthusiasm and Exposure}

Another factor that has been a key to second language learning has to do with the readiness of the individual as well as how excited the individual is to learn the second language. According to Brophy (2010), motivation is the degree to which learners could devote time and energy towards different responsibilities, objectives or actions. Learner's inspiration could influence the existing learning in addition to the abilities and approaches studied hitherto (Schunk et al., 2008). Inspiration is the power that propels an individual to attain an objective. On the contrary, the absence of motivation makes the learning process highly difficult. Enthusiasm is the tenets, principles and conducts that drive the learning process. Some dynamic tenets could result in enthusiasm; however, other principles could result in resolute industriousness. By motivating students, teachers get them to learn better.

All things being equal, people have the equal capability to learn a language. However, the social environment has an excessive influence toward learning since a person learns the language that he is exposed to and not necessarily the mother tongue. Exposure is of great essence since it enables the learners to have replicas to follow and to have appraisals between varieties of a language (MacIntyre, Baker, Clément and Donovan, 2002).

\section{Phonetic Capability}

It is reported that learners living in English-speaking localities are likely to attain better pronunciation since they are enthralled in the language. Nevertheless, not all learners are raised in an English-speaking background. Learners possess varied phonetic capabilities as a result of their biological and physiological variations. Some are superior at replicating sounds than others. The point to which they have the exposure to English daily could tell how fast they will be improving their pronunciation. A child is born with the capability to learn any language and possibly with the tangible knowledge of linguistics universals. Hence, the interplay between the native environment and a second language is perceived as a key factor in language learning effectiveness (Freeman \& Freeman, 2011; Ellis \& Shintani, 2014). 


\section{Attitude}

A number of scholars have discovered that learners with affirmative attitudes relative to the learning the English language learn quicker, and learners who are unaffectedly open-minded and fascinated in refining their pronunciation usually achieve that aim. Dornyei, (2003), for instance, maintains that attitudes are created and could be altered through family, teachers, peers and the school.

The attitude of students towards the learning of pronunciation is a major challenge in the studying of pronunciation. In fact, majority of teachers and learners, including most teachers of English in Ghana do not place much emphasis on learning pronunciation (Asante-Nimako, 2018).

\section{Research Methodology}

The study adopted the descriptive and analytic statistic method for the collection and analysis of data from Osei Kyeretwie Senior High School. Recording test was administered on the learners and a questionnaire was administered to tutors to write their views and ideas regarding the problem under investigation. The data was analyzed descriptively and through the thematic approach.

\section{Population and Sampling}

The total population of the final students in the Osei Kyeretwie Senior High school was 300 while the languages department had a total number of 45 teachers of English. The sample was made up of 50 final year students and 25 teachers who were randomly selected to participate in the study.

\section{Data Analysis}

In analyzing the data, the researchers employed two approaches. Firstly, the descriptive approach was employed to the recordings that were taken from the learners. Responses from the questionnaire with teachers, on the other hand, were analyzed through the thematic approach.

\section{Data analysis and Results}

The results and discussion section was guided by key research questions that guided the study as follows:

Research Question 1: What are the challenges of second language learners in English pronunciation among the Osei Kyeretwie Senior High School Students?

This question was answered through the data from the questionnaire as well as from the recordings. The recording test was a very significant tool since it conforms to the objective of the study which was to discover the difficulties learners at the senior high school faced in learning pronunciations. It also provided the first-hand opportunity to determine what the challenges were directly from the students so that those suggested by the teachers through the questionnaire could lend further clarifications to the issue.

The recorded test was discoursed and examined in testing the inaccuracies of the pronunciation of the students. Ten sentences were typed on a paper and each sentence had a target sound. For instance, the word AMOUNT could be placed in a sentence, and the researchers watched out how the participants would articulate the sound /ə/ in the word.

After recording the pronunciation of the 50 learners, the researchers went on to listen to the recorded pronunciations several times and then recorded the number of learners who produced the words correctly and that of those who produced them incorrectly. The data were examined descriptively after which the researchers computed and recorded the percentages.

The results reveal that in the experiment of $/ \wedge /$ sound in the word 'front', for instance, only 5 out of the 50 learners $(10 \%)$ could pronounce it correctly. Therefore, the majority $(90 \%)$ of the learners under investigation could not produce it correctly. The outcome of the recording, therefore, shows that the learners do have challenges related to pronunciation. The entire outcome of the recording test is indicated in table 1.

Table 1: The pronunciation of Some English Vowels by the Sample Students

\begin{tabular}{|c|c|c|c|c|c|c|}
\hline Word & $* \mathrm{TS}$ & ${ }^{*} \mathrm{NS}$ & ${ }^{*} \mathrm{NSC}$ & $\%$ & ${ }^{*} \mathrm{NSI}$ & $\%$ \\
\hline Wrote & /əठ/ & 50 & 8 & 16 & 42 & 84 \\
\hline Make & /eı/ & 50 & 18 & 36 & 32 & 64 \\
\hline Front & $/ \wedge /$ & 50 & 5 & 10 & 45 & 90 \\
\hline Put & / / & 50 & 6 & 12 & 54 & 88 \\
\hline
\end{tabular}

Note. ${ }^{*} \mathrm{TS}=$ Target Sound, $* \mathrm{NS}=$ Number of Learners, $* \mathrm{NSC}=$ Number of Learners with Correct pronunciation, $*$ NSI $=$ Number of Learners with Incorrect Pronunciation. 
Table 1 further indicates that 8 out of 50 students representing $16 \%$ could produce the target sound /əo/ in the word 'wrote' correctly while 42 participants representing $84 \%$ produced it incorrectly. In the word "make", only 18 students out of 50 representing $36 \%$ produced the target sound /el/ correctly with 32 representing $64 \%$ not being able to pronounce it correctly. Lastly, for the word "put", only 6 out of the 50 learners, representing $12 \%$ could produce the target sound $\mathrm{l} / \mathrm{/}$ correctly. From the analysis so far, it was confirmed that majority of the participants was challenged in relation to producing the vowels correctly. These results confirm that pronunciation challenges exist among senior high school students.

The findings agree with the existing literature whereby findings on the nature of pronunciation in Ghana indicate that there is vowel length neutralization, reduction of diphthongs to monothongs and fronting and backing of low vowels (Koranteng, 2006; Huber, 2008; Simo Bobda, 2000; Adjaye, 2005; Kpeglo and Temadonku, 2016). Therefore, English pronunciation is a real problem in Ghana. This partly explains why proactive steps have to be taken to curb the pronunciation challenges encountered by the learners in Ghana.

Table 2: The Production of Some English Consonants by the Sample Students

\begin{tabular}{lllllll}
\hline Word & $*$ TS & $*$ NS & $*$ NSC & $\%$ & *NSI & $\%$ \\
\hline Vision & $/ 3 /$ & 50 & 13 & 26 & 37 & 74 \\
Third & $/$ / & 50 & 15 & 30 & 35 & 70 \\
Think & $/ \Theta /$ & 50 & 18 & 36 & 32 & 64 \\
Jumped & $/ \mathrm{t} /$ & 50 & 8 & 16 & 42 & 84 \\
\hline
\end{tabular}

Note. ${ }^{*} \mathrm{TS}=$ Target Sound, ${ }^{*} \mathrm{NS}=$ Number of Learners, ${ }^{*} \mathrm{NSC}=$ Number of Learners with Correct pronunciation, ${ }^{*} \mathrm{NSI}=$ Number of Learners with Incorrect Pronunciation.

While the results from Table 1 point to the challenges in pronunciation of English vowel sounds, Table 2 outlines results based on pronunciation of consonant sounds.

Table 2 indicates that only 13 out 50 participants representing $26 \%$ could correctly produce the target sound /3/ in the word "vision", with 37 representing $74 \%$ having challenges producing it appropriately. In the second word 'third', 15 out of 50 representing $30 \%$ could produce the target sound /ठ/ correctly while 35 representing $70 \%$ could not produce it correctly. In the word "think", only 18 participants representing $36 \%$ could produce the target sound $/ \Theta /$ correctly with 32 representing $64 \%$ not being able to produce it correctly. Lastly, out of 50 students, only 8 representing $16 \%$ could produce the target sound / $t$ / in the word "jumped" correctly and 42 representing $84 \%$ could not produce it accurately. This analysis indicates that, like in the vowel sounds, majority of the students had difficulties producing the target consonant sounds correctly. It is important to note that difficulties in the third sound / $t$ / in the word "jumped" could be attributed to a phonological rule that is absent in Akan. This rule states that in English, when /ed/ comes after a voiceless consonant, it is produced as /t/ (Roach, 2002).

Moreover, these findings on the deficiencies in the pronunciation of consonants among the learners present a part of the problem as existing studies on
Ghanaian English have reported regarding the reduction of consonant clusters. In the case of $/ \theta /$ and /ð/, they are replaced by alveolar plosives $/ t$, $\mathrm{d} /$ or dental plosives / $\mathrm{t}, \mathrm{d} / \mathrm{in}$ initial or medial position, but in final positions, dental fricatives may either be replaced by /f/ or dropped entirely. There are cases of affricated forms such as /dð, d $\theta /$ in the English pronunciations of educated Ghanaians (Huber, 2008). Koranteng (2006) reports that the dental fricatives, $/ \theta /$ and /ð/, are phonemic in GhE, but they sometimes oscillate in their use as Ghanaian speakers switch to /t/ and /d/ unconsciously when they speak quickly (Koranteng 2006). All these reveal the challenges the learners under investigation experienced in English pronunciation.

Research Question 2: What are the areas of difficulty and the contributing factors toward the pronunciation challenges among the learners under investigation?

Table 3 (p. 125) presents the results from the questionnaire on areas of difficulty and the contributing factors toward the pronunciation challenges among the learners under investigation. Particularly, $69 \%$ of the respondents agreed that stress and intonation was the central difficulty in pronunciation. Again, $76 \%$ of the respondents revealed that the $L_{1}$ (mother tongue) of learners adversely impacted the pronunciation process and $77 \%$ indicated that poor syllabus structure was the 
major issue that affected the punctuation among the learners under investigation. Furthermore, the majority $(88 \%)$ indicated that unskilled tutors are the reason for the poor pronunciation among the learners under investigation. Therefore, the first language, the poor syllabus and the unskilled tutors are the responsible factors for poor pronunciation among the learners under investigation.

Table 3: Areas of Difficulty and Contributing Factors

\begin{tabular}{lccc}
\hline \multicolumn{1}{c}{ Questionnaire item } & Disagree & Somehow & Agree \\
\hline Poor stress intonation & $8 \%$ & $23 \%$ & $69 \%$ \\
$\mathrm{~L}_{1}$ interference & $10 \%$ & $14 \%$ & $76 \%$ \\
Poor syllabus structure & $1 \%$ & $22 \%$ & $77 \%$ \\
Unskilled Tutors & $1 \%$ & $11 \%$ & $88 \%$ \\
\hline
\end{tabular}

Asante-Nimako, D.A.M. (2018). "Problems Related

The literature further supports how an individual's mother tongue is capable of interfering in the learning of a second language (Brown, 2000). Therefore, the findings are in harmony with the existing body of knowledge.

\section{Conclusion and Recommendations}

Based on the findings, the following are conclusions and recommendations of the study.

\section{Conclusions}

The study concludes that a large number of the learners mispronounced selected vowels and consonants, thus confirming the reality that pronunciation problem persist in Ghanaian secondary schools. The problem of poor pronunciation was found to be related to the teaching and learning strategies employed in teaching pronunciation, unskilled teachers and the influence of mother tongues.

\section{Recommendations}

Based on the conclusions of the study, it is recommended that teacher trainees in English language from institutions of higher learning should be exposed to the appropriate strategies of teaching good pronunciation. Furthermore, regular in-service training should be organized for the teachers of English in senior high schools across the country of Ghana to equip them with the current approaches to teaching pronunciation. Lastly, stakeholders of education in the country should provide wellresourced language laboratories for senior high schools to enable students to practice phonetics effectively.

\section{Reference}

Adjaye, S.A. (2005). Ghanaian English Pronunciation, New York \& Ontario: The Edwin Mellen Press. to the Teaching of English Pronunciation in Pre-service Institutions: A Study at the Wesley College of Education, Kumasi, Ghana." IJALEL 7(6):37-47.

Brophy, J. (2010). Motivating students to learn (3rd ed.). Madison Avenue, NY: Routledge.

Brown, H. D. (2000). Principles of Language Learning and Teaching ( $4^{\text {th }}$ ed.) NY: Addison Wesley Longman, Inc.

Birdsong, D. (2004). Second language acquisition and ultimate attainment. In A. Davies \& C. Elder (Eds.), The handbook of applied linguistics (pp. 82-105). Malden, MA: Blackwell.

Crystal, D. (2003). English as a Global Language. Cambridge: University Press.

Derwing, T. M., \& Munru, M. J. (2005). Second language accent and pronunciation teaching: A researcher-based approach. TESOL Quarterly, 39(3), 379-397. http://dx.doi.org/ doi:10.2 307/3588486

Dornyei, Z. (2003) Attitudes, and Motivations in Language Learning: advance in theory, research, and applications. In Attitudes, Orientation, and Motivations in Language Learning. In Despagne (2010) the difficlties of learning English. Perceptions and attitudes in Mexico.

Ellis, R., \& Shintani, N. (2014). "Instructed second language acquisition". In exploring language pedagogy through second acquisition research. New York: Routledge.

Freeman, D. E., \& Freeman, Y. S. (2011). Essential Linguistics: What teachers need to know to teach ESL, reading, spelling, and grammar. Portsmouth, $\mathrm{NH}$ : Heinemann.

Homidan, A. H. (1984). Utilizing the Theory of Articulatory Settings in the Teaching of 
English Pronunciation to Saudi Students Learning English as a Second Language. Doctoral Dissertation, King Fahd Public Library.

Huber, M. (2008). Ghanaian English: Phonology. In R. Mesthrie (ed.), Varieties of English: Africa, South and Southeast Asia. Berlin: Mouton de Gruyter, 67-92.

Koranteng, L. (2006). Ghanaian English: A Description of the Sound System and Phonological Features (PhD Dissertation). University of Ghana, Legon

MacIntyre, P. D., Baker, S. C., Clément, R., \& Donovan, L. A. (2002). "Sex and age effects on willingness to communicate, anxiety, perceived competence, and L2 motivation among junior high school French immersion students". Language Learning, 52(3), 537564.

Moosa, M. H. (1972). Difficulties of Learning the Pronunciation and Structural Differences between Arabic and English. MA Dissertation, Library of Saudi Arabia, Educational mission; Texas.

Muñoz, Carmen \& Singleton, David. (2011). "A critical review of age-related research on $\mathrm{L} 2$ ultimate attainment". Language Teaching. 44. 1 - 35. 10.1017/S0261444810000327.

Nation, I. S. P., \& Newton, J. (2009). Teaching ESL/EFL listening and speaking. New York: Routledge, Taylor and Francis.

O'Connor, J. D. (1997). Better English Pronunciation. Cambridge: University Press.

Roach, P. (2002). English Phonetics and Phonology. Cambridge: University Press.

Schaetzel, K. (2009). Teaching Pronunciation to Adult English Language Learners. Washington, DC: CAELA Network Brief.

Schunk, D. H., Pintrich, P. R., \& Meece, J. L. (2008). Motivation in education: Theory, research, and application (3rd ed.). Upper Saddle River, NJ: Merrill/Prentice-Hall.

Simo Bobda, A. (2000). "The Uniqueness of Ghanaian English Pronunciation in West Africa", Studies in the Linguistic Sciences, Vol. 30, No. 2, pp.185-198. Social media statistics/Ghana.html).

Yule, G. (2017). The Study of Language (6 $6^{\text {th }}$ ed.). Cambridge University Press. 